\title{
The underlying factors of a successful organisational digital transformation
}

\begin{tabular}{|c|c|}
\hline \multicolumn{2}{|c|}{ 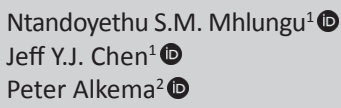 } \\
\hline \multicolumn{2}{|c|}{$\begin{array}{l}{ }^{1} \text { Gordon Institute of Business } \\
\text { Science, University of } \\
\text { Pretoria, Johannesburg, } \\
\text { South Africa }\end{array}$} \\
\hline \multicolumn{2}{|c|}{$\begin{array}{l}{ }^{2} \text { Business Banking Division, } \\
\text { First National Bank, } \\
\text { Johannesburg, South Africa }\end{array}$} \\
\hline \multicolumn{2}{|c|}{$\begin{array}{l}\text { Corresponding author: } \\
\text { Jeff Chen, } \\
\text { chenj@gibs.co.za }\end{array}$} \\
\hline \multicolumn{2}{|c|}{$\begin{array}{l}\text { Dates: } \\
\text { Received: } 03 \text { May } 2018 \\
\text { Accepted: } 08 \text { Nov. } 2018 \\
\text { Published: } 30 \text { Apr. } 2019\end{array}$} \\
\hline \multicolumn{2}{|c|}{$\begin{array}{l}\text { How to cite this article: } \\
\text { Mhlungu, N.S.M., Chen, J.Y.J. \& } \\
\text { Alkema, P., 2019, 'The } \\
\text { underlying factors of a } \\
\text { successful organisational } \\
\text { digital transformation', } \\
\text { South African Journal of } \\
\text { Information Management } \\
\text { 21(1), a995. https://doi.org/ } \\
10.4102 / \text { sajim.v21i1.995 }\end{array}$} \\
\hline \multicolumn{2}{|c|}{$\begin{array}{l}\text { Copyright: } \\
\text { ( } 2019 \text {. The Authors. } \\
\text { Licensee: AOSIS. This work } \\
\text { is licensed under the } \\
\text { Creative Commons } \\
\text { Attribution License. }\end{array}$} \\
\hline \multicolumn{2}{|c|}{ Read online: } \\
\hline 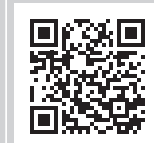 & $\begin{array}{l}\text { Scan this QR } \\
\text { code with your } \\
\text { smart phone or } \\
\text { mobile device } \\
\text { to read online. }\end{array}$ \\
\hline
\end{tabular}

Background: Organisational digital transformation (ODT) is a field of growing interest in practice and academia. Further, a disparity between how information technology (IT) leaders and non-IT leaders perceive the factors leading to successful ODT initiatives has been cited. A set of empirically tested ODT assessment instruments will enhance leaders' decision-making when implementing ODT initiatives.

Objectives: This research attempts to: (1) identify the key internal factors of successful ODT initiatives; and (2) confirm whether there is, as has been suggested, a difference between the way IT managers and non-IT managers perceive these factors.

Method: A questionnaire consisting of 36 potential underlying factors was formulated, based on the existing literature and additional insights. A prescreening process ensured each survey participant met the selection criteria. From a total of 95 participants who completed the survey, 45 were IT executives and 50 were non-IT executives. Quantitative analyses were conducted to identify the key underlying factors and ascertain whether IT and non-IT leaders hold differing perceptions of these factors.

Results: Factor analysis identified four categories of factors of a successful ODT initiative: (1) customer centricity, (2) governance, (3) innovation and (4) resource attainment. Further, the analysis revealed that IT and non-IT managers hold similar perceptions on the key factors affecting the overall ODT success.

Conclusion: This research provides empirical evidence that paves the way towards a reliable ODT assessment instrument and refutes claims that IT and non-IT leaders hold contrasting views on these factors.

Keywords: Digital transformation; organisational transformation; innovation, digital strategy; organisational digital transformation assessement.

\section{Introduction}

Owing to the rapid rate of digital change, organisations are compelled to increase the pace of their digital transformation by revising and overhauling outdated offerings and processes (Westerman et al. 2012). Few organisations will be spared from the disruptive impact of ever-increasing competition brought about by technology advancement and the evolution of business models (Fitzgerald et al. 2013). To navigate the complexity associated with an organisation's digital transformation, many leaders find themselves overwhelmed as to how they should orient their digital transformation strategy prior to embarking on such an initiative (Kane et al. 2015, 2016). Unpacking the key underlying factors affecting the organisational digital transformation (ODT) can greatly assist the leaders to streamline their investments, develop a comprehensive digitisation roadmap and explore new digitalisation opportunities (Abolhassan 2017; Matt, Hess \& Benlian 2015; Westerman et al. 2011).

There remains no consensus in the literature on a definition of ODT. Westerman et al. (2011) consider digital transformation as the use of technology to radically improve the performance of enterprises. In contrast, Fitzgerald et al. (2013) regard digital transformation as the use of new digital technologies (social media, mobile, analytics or embedded devices) to enable major business improvements (such as enhancing customer experience, streamlining operations or creating new business models). These interpretations of ODT represent a narrow view, with emphasis on the 'use of digital technologies'. In contrast, Kane et al. (2015) propose that the success of an ODT initiative does not stem from the appropriate use of technology only but is more dependent upon having a clear and effective digital strategy endorsed by leaders. Matt et al. (2015) similarly advocate the importance of taking on a business-centric perspective to view ODT 
and describe ODT as the strategies that 'focus on the transformation of products, processes, and organisational aspects owing to new technologies'. For the purposes of this research, we have adopted the views proposed by Kane et al. (2015) and Matt et al. (2015) owing to the increasing support of literature (Berman 2012; Desmet et al. 2015; Kane et al. 2016; Oswal \& Kleinemeier 2017; Wade 2015). We define ODT as the strategic interventions that enhance the organisational digital capability with the purpose of improving the organisation's processes, products, services and business models to satisfy their customers.

\section{Underlying factors affecting the success of organisational digital transformation}

A range of underlying factors affecting the overall success of ODT have been proposed by various scholars. Several recent studies suggest organisational structure and culture are significant factors of ODT (Kane et al. 2016; Wade 2015; Westerman et al. 2014). One study found that customer centricity, in the form of improving the customer experience, customer service and customer value proposition, is the critical factor driving ODT (Berman 2012). Corporate innovation, customer centricity, business models, governance and technology-related aspects have also been posited as the building blocks for achieving digital transformation (Desmet et al. 2015; Oswal \& Kleinemeier 2017).

Table 1 presents 16 major factors identified from extant literature on ODT. However, many of these propositions lack the support of empirical evidence, despite having been vigorously debated. MIT Sloan Management Review and Deloitte addressed the lack of consensus with a global study of 4800 executives, managers and analysts in 2014 (Kane et al. 2015). However, the results added to the lack of consensus with their unearthing of potential factors not identified or studied elsewhere, such as the utilisation of innovative financing models and creation of a supportive collaboration with suppliers and customers. We believe that an ODT initiative is likely to fail when organisations do not establish the appropriate funding mechanisms and acquire the key resources to support the initiative.

In short, the total number of empirical studies on the underlying success factors of ODT is limited; extant studies do not exhibit uniformity in the factors identified; and a number of the factors identified in the literature, such as strategic procurement and innovative funding models, have received insufficient examination and explanation to serve as a foundation for development of an ODT assessment instrument.

\section{Information technology and non-information technology leaders' perceptions}

Research suggests that leaders' contrasting interpretations of ODT are often associated with their different professional

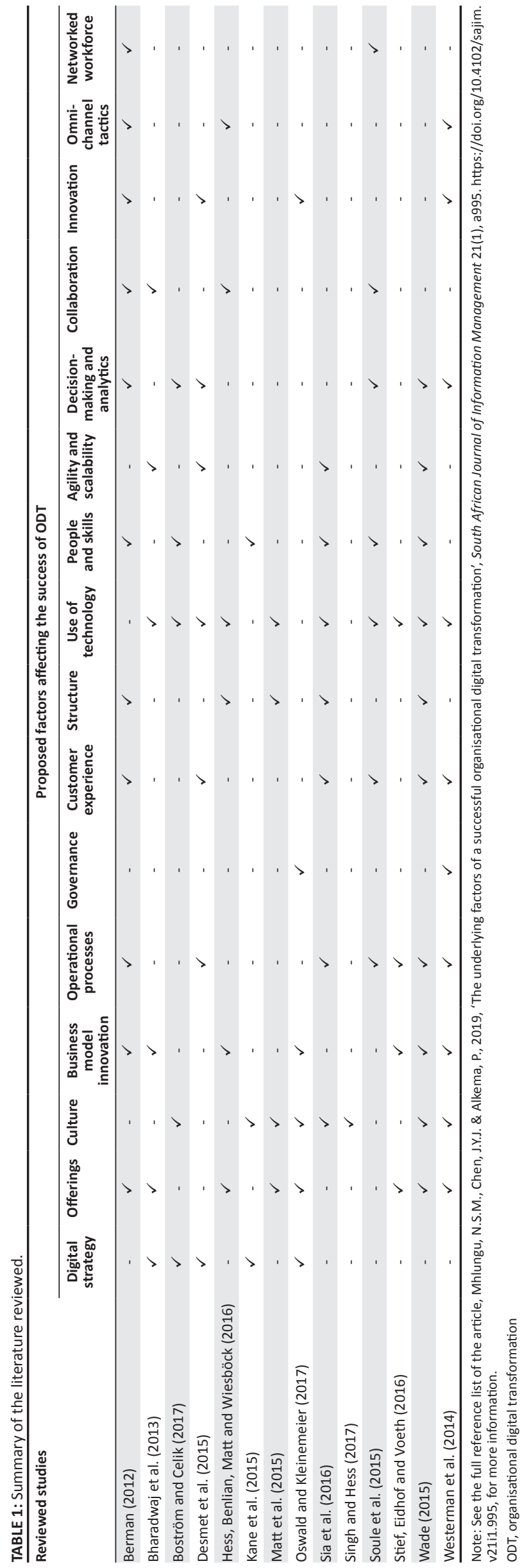


capacities (Westerman et al. 2014). Gerth and Peppard (2016) note that the failure of ODT initiatives is often blamed on IT leaders who lack a broader understanding of the key factors affecting such major undertakings. Singh and Hess (2017) claim that senior leaders in charge of the IT divisions are often pure technologists who focus more on the technology than the needs of the customers; while senior leaders responsible for non-IT divisions act as business strategists, and treat technology as a means to a greater end. An IT executive may understand digital transformation as an adoption of cloud technologies, while a marketing leader may consider it a move towards e-commerce or social media, and a financial leader may interpret it as a novel payment platform or data analytics (Westerman et al. 2011). Such misalignment diminishes success rates of ODT initiatives.

In contrast, a study by the Economist Intelligence Unit (2016) suggests that IT and non-IT executives hold similar understandings of the role of ODT initiatives and the factors that drive their success. Thus, while there is a strand of research suggesting contrasting stances between IT and nonIT leaders on the factors underlying successful ODT initiatives, this is far from an established phenomenon. This lack of consensus in the literature informs the second aim of this study to test the hypothesis that these two groups view these factors differently.

\section{Research methodology}

This article set out to determine the underlying factors of success for ODT initiatives and, secondarily, to test the hypothesis that IT and non-IT leaders perceive these differently.

\section{Data collection}

A prescreening process was conducted to ensure each invited survey participant met the selection criteria before taking part in this research. The criteria applied were as follows:

- Participants must work for a large organisation (defined as 5000 employees or more) within the private sector. This criterion was to prevent this research from being diluted by comparing the dynamics within large enterprises against those from small and medium-sized enterprises or public agencies.

- Participants' employer business must comprise a strong business-to-consumer portfolio. This was to ensure the capacity to test ODT success factors relating to customer centricity.

- Participants' organisations must have previously undergone a process that meets the definition of ODT as defined above.

- The headquarters of each participant's firm must be located within the country (South Africa). This stipulation ensured that each participant's organisation had the autonomy to drive its own ODT agenda, independent of a foreign head office.
- Participants must each hold a decision-making role in a unit whose success could be affected by digital trends. This limitation ensured targeting only senior leaders with a vested interest in ODT.

Sixty companies and two hundred fifty potential participants were preselected to participate in the survey. Only 136 of the potential respondents were invited to complete the survey based on the data collection criteria described.

\section{Establishing the underlying factors of successful organisational digital transformation initiatives}

A quantitative research methodology was adopted to identify the factors underlying successful ODT initiatives. To construct the list of potentially significant underlying success factors for ODT initiatives and test their validity, this study adapted Benson and Clark's (1982) instrument development process. This required the identification of the relevant literature and a subsequent analysis to identify factors explicitly or implicitly unearthed in these studies. This process discerned 36 factors posted by the academic literature as significant determinants of the success of an ODT initiative. These formed the list of potential underlying factors to be tested with a sevenpoint Likert scale questionnaire. On the questionnaire, the participants scored the importance of 36 items ( $1=$ least important and $7=$ most important). This questionnaire is reproduced in Table 2.

An exploratory factor analysis (EFA) was carried out on the collected research data as it is well-suited for developing a new instrument or scale (Fabrigar et al. 1999; Yong \& Pearce 2013). The principal axis factoring (PAF) method was deployed to identify the underlying structure of the ODT assessment instrument. The PAF method has been recommended for recovering weak factors when sample sizes are small and when the data severely violates the assumption of multivariate normality (Creswell 2012; De Winter \& Dodou 2012; Fabrigar et al. 1999). Principal axis factoring zeroes in on the shared (common) variance between the observed variables and explains the latent factors underlying the data (Fabrigar et al. 1999). The face value validity and content validity of the ODT assessment instrument was investigated.

\section{Comparing information technology and non- information technology leaders' perceptions}

The Cronbach's alpha of each factor was analysed to establish the internal reliability. Cronbach's alpha measures the consistency of responses across all questions or subgroups of questions and is the most frequently used method for testing internal consistency (Saunders, Thornhill \& Lewis 2015). After the key dimensions of factors were identified as the result of the above procedures, this study investigated whether IT and non-IT senior leaders hold different perceptions on the underlying factors of successful ODT initiatives. For each dimension of factors uncovered, the 
Kruskal-Wallis H test was conducted based on the following hypotheses:

$\mathbf{H}_{0}$ : There is no difference in the way that IT and non-IT managers regard the importance of that particular dimension of underlying factors.

TABLE 2: Extract of research questionnaire.

Item Observed variables and latent constructs

Q1 Mechanisms to keep abreast with the changing 'customers' needs (both internal and external customers)

Q2 Scenario planning (corporate foresight capability)

Q3 Data-driven decision-making (leverage the insights generated from data to shape organisational strategy)

Q4 Integrate business strategies (alignment between all business strategies for IT-business alignment)

Q5 Embed IT strategy in divisional strategies (organisational IT strategy is applied in different divisional units)

Q6 Customer-centred approach in offering design (for both internal and external customers)

Q7 Leaders' technology awareness (leaders familiar with the capability of the technological offerings)

Q8 Coherency (reduced politics across the organisation)

Q9 Transformational culture (organisational culture embracing change and high performance)

Q10 Organisational structure refinement (fine-tuning and redesign)

Q11 Decentralisation of authority (certain level of autonomy)

Q12 Silo prevention (role clarity, collaboration, resource sharing and effective communication)

Q13 Multichannel or omni-channel operations (integration of delivery platforms)

Q14 Process digitisation and re-engineering (both internal services and customer services)

Q15 Prioritisation of digital projects (establish priority and roadmap)

Q16 Coordination of portfolio of initiatives (coordination of portfolio of initiatives to scale the change)

Q17 Change campaigns (from marketing, communication, progress assessment, to impact measurement)

Q18 Urgency and efficiency (adopting and cascading agile methodologies to enable agility and speed)

Q19 Governance and policies redefined (guiding policies and decision structures to steer the transformation)

Q20 Security policies and protocol upgrade (security systems, standards and practices used to secure data)

Q21 Clearly defined M\&E criteria (evaluation of IT controls, that is, security metrics, vulnerability assessment)

Q22 Integration of the new and the old IT enterprise (legacy systems management and shadow IT integration)

Q23 Scaling of infrastructure on demand (ability to increase capacity in an adaptive way)

Q24 Experimentation (purposeful and frequent experimentation with new technologies)

Q25 External start-up involvement (with SMMEs, start-ups and other external business entities)

Q26 Platforms (creating own platform and/or plugging into other platforms)

Q27 Engagement model (capability to communicate with the rest of the organisation and external customers)

Q28 Multilevel skills development (holistic approach, multifaceted skills, from soft skills to technology skills,

Q29 Employee KPI embeddedness (clearly defined KPIs, aligned to strategic objectives)

Q30 Rewards and recognition (incentive to motivate employee entrepreneurial endeavours)

Q31 Well-structured innovation throughput mechanism (from idea generation to implementation of new ideas)

Q32 Exploration of new digital business model(s) (testing new business models enabled by digital technology)

Q33 Innovation outpost (established a dedicated unit to promote corporate innovation)

Q34 Procurement strategies (to buy, to rent or to adopt other creative means to acquire resources)

Q35 Innovative financing models (creative ways to raise funds and/or bespoke payment methods)

Q36 Creative partnership (secure funding, infrastructure and expertise from internal and/or external suppliers

M\&E, monitoring and evaluation; SMMEs, Small, Medium and Micro-sized Enterprises
$\mathbf{H}_{\mathbf{1}}$ : There is a difference in the way that IT and non-IT managers regard the importance of that particular dimension of underlying factors.

The exact hypotheses are listed in the following section.

\section{Results}

The response rate was $69.85 \%(n=95)$ and the respondents came from 34 organisations across 9 different industries (Table 2 and 3). The 95 respondents were made up of 45 IT leaders and 50 non-IT leaders. This sample size met the recommended minimum subject-to-variables ratio of 2:1 for conducting EFA with small sample sizes (Barrett \& Kline 1981; De Winter, Dodou \& Wieringa 2009).

\section{Underlying success factors of organisational digital transformation initiatives}

The calculated Mahalanobis distances (MDs) were used to identify multivariate outliers based on a chi-square test, assessed using a $p$-value of $p<0.001$. Four cases $(n=95)$ were identified as outliers because they had maximum MDs (56.220; 51.079; 50.341; 47.076; 42.607) larger than their critical chisquare values $(d f=15)$ assessed at a critical alpha of 0.001 . The identified outliers were not deleted because PAF does not require the multivariate normal assumption (Wang \& Du 2000).

The Shapiro-Wilk test $(p>0.05)$ used to test for multivariate normality indicated that all 15 observed variables had a $p$-value (Sig. $=0.000)$ that was below 0.05. Therefore, the null hypothesis $(p>0.05)$ stating that data is normally distributed was rejected. As such, we concluded that the multivariate normality assumption was violated. Fabrigar et al. (1999) recommend principal factoring methods if the assumption of multivariate normality is severely violated. Therefore, the PAF method was used to conduct EFA. Applying Norman (2010), parametric statistics (i.e. EFA) can safely be used with a Likert scale, with non-normal distributions, with small sample sizes and with unequal variances.

The linearity assumption was tested by inspecting the correlation matrix for correlation coefficients greater than 0.3. The correlation matrix indicated that all variables had linear relationships (correlation coefficient $>0.3$ ) with one or more variables. As such, the required linearity assumption

TABLE 3: Total number of survey respondents by industry $(n=95)$.

\begin{tabular}{lcc}
\hline Valid & Frequency $(\boldsymbol{n})$ & $\mathbf{\%}$ \\
\hline Financial services (banking, insurance) & 32 & 34 \\
Other & 18 & 19 \\
Manufacturing & 10 & 11 \\
Information technology & 6 & 6 \\
Mining & 6 & 6 \\
Logistics and supply chain & 6 & 6 \\
Retail and wholesale & 5 & 5 \\
Management consulting & 4 & 5 \\
Telecommunications & 4 & 4 \\
Engineering & 4 & 4 \\
\hline Total & $\mathbf{9 5}$ & $\mathbf{1 0 0}$
\end{tabular}


TABLE 4: Total variance explained by extracted factors.

\begin{tabular}{|c|c|c|c|c|c|c|c|c|c|}
\hline \multirow[t]{2}{*}{ Factor } & \multicolumn{3}{|c|}{ Initial eigenvalues } & \multicolumn{3}{|c|}{ Extraction sums of squared loadings } & \multicolumn{3}{|c|}{ Rotation sums of squared loadings } \\
\hline & Total & $\%$ of variance & Cumulative \% & Total & $\%$ of variance & Cumulative \% & Total & $\%$ of variance & Cumulative \% \\
\hline 1 & 5.443 & 36.288 & 36.288 & 5.051 & 33.672 & 33.672 & 2.836 & 18.907 & 18.907 \\
\hline 2 & 2.195 & 14.631 & 50.918 & 1.893 & 12.620 & 46.292 & 2.263 & 15.090 & 33.997 \\
\hline 3 & 1.662 & 11.079 & 61.998 & 1.255 & 8.369 & 54.661 & 2.128 & 14.185 & 48.182 \\
\hline 4 & 1.272 & 8.483 & 70.480 & 0.917 & 6.116 & 60.776 & 1.889 & 12.594 & 60.776 \\
\hline 5 & 0.693 & 4.620 & 75.101 & - & - & - & - & - & - \\
\hline 6 & 0.646 & 4.307 & 79.408 & - & - & - & - & - & - \\
\hline 7 & 0.613 & 4.088 & 83.496 & - & - & - & - & - & - \\
\hline 8 & 0.555 & 3.703 & 87.199 & - & - & - & - & - & - \\
\hline 9 & 0.447 & 2.981 & 90.180 & - & - & - & - & - & - \\
\hline 10 & 0.338 & 2.252 & 92.432 & - & - & - & - & - & - \\
\hline 11 & 0.319 & 2.130 & 94.562 & - & - & - & - & - & - \\
\hline 12 & 0.267 & 1.778 & 96.340 & - & - & - & - & - & - \\
\hline 13 & 0.234 & 1.562 & 97.902 & - & - & - & - & - & - \\
\hline 15 & 0.136 & 0.906 & 100.000 & - & - & - & - & - & - \\
\hline
\end{tabular}

for conducting factor analysis was satisfied. To test for multicollinearity, we ran SPSS v24 bivariate correlation analysis to identify variables with high correlations $(>0.9)$ that could cause multicollinearity. SPSS v24 was used for linear regression (collinearity diagnostic) to identify multicollinearity by assessing the variance inflation factor of all 36 variables. The result confirmed that the multicollinearity assumption was satisfied.

The Kaiser-Meyer-Olkin measure (KMO) of sampling adequacy and Bartlett's test of sphericity were used to examine the factorability assumption. The measures of sampling adequacy (KMO and Bartlett's test) indicated that the factorability assumption was satisfied. The KMO was more than $0.6(\mathrm{KMO}=0.782)$ and the Bartlett's test of sphericity was significant $\left(X^{2}[630]=2077.683, p<0.001\right)$, indicating a factorable correlation matrix. The initial solution suggested a nine-factor solution based on eigenvalues $>1.0$. The KMO was more than 0.6 $(\mathrm{KMO}=0.732)$ and Bartlett's test of sphericity was significant $\left(X^{2}[630]=2077.683, p<0.001\right)$, indicating a factorable correlation matrix. Based on the measures of the sampling adequacy results, it was concluded that the factorability assumption was satisfied (Table 4).

Initially, 36 items were constructed as the latent variables. The final PAF varimax rotation solution extracted four factors and a total of 15 items. Table 5 provides the SPSS output of the rotated factor matrix, which demonstrates adequate convergent validity for all four factors because all loadings were above the minimum threshold of 0.4 . These four factors explained $63.9 \%$ of the total variance within the observed data. The factors were: customer centricity $(28.7 \%)$, governance $(13.1 \%)$, innovation $(11.6 \%)$ and resource attainment $(10.5 \%)$. All four factors had a Cronbach's alpha more than 0.7 , which is considered an indicator of good internal consistency (Zikmund et al. 2010). The Cronbach's alpha values for customer centricity, governance, innovation and resource attainment were $0.840,0.779,0.799$ and 0.864 , respectively. Content validity and face validity of the ODT assessment instrument was established based on the literature presented in Table 1.
TABLE 5: Rotated factor matrix.

\begin{tabular}{|c|c|c|c|c|}
\hline \multirow[t]{2}{*}{ Variable } & \multicolumn{4}{|c|}{ Factor } \\
\hline & 1 & 2 & 3 & 4 \\
\hline \multicolumn{5}{|l|}{ Customer centricity $(\alpha=0.840)$} \\
\hline $\begin{array}{l}\text { 1. Customer-centred approach in designing } \\
\text { offerings (Q6) }\end{array}$ & 0.748 & - & - & - \\
\hline $\begin{array}{l}\text { 2. Mechanisms to keep abreast with changing } \\
\text { customer needs (Q1) }\end{array}$ & 0.718 & - & - & - \\
\hline 3. Process digitisation and re-engineering (Q14) & 0.697 & - & - & - \\
\hline 4. Prioritisation of digital projects (Q15) & 0.644 & - & - & - \\
\hline $\begin{array}{l}\text { 5. Experimentation with new technologies to } \\
\text { meet customer needs (Q24) }\end{array}$ & 0.606 & - & - & - \\
\hline \multicolumn{5}{|l|}{ Governance $(\alpha=0.779)$} \\
\hline $\begin{array}{l}\text { 1. Clearly defined M\&E criteria and } \\
\text { mechanisms (Q21) }\end{array}$ & - & 0.902 & - & - \\
\hline $\begin{array}{l}\text { 2. Up-to-date security systems, standards and } \\
\text { practices (Q20) }\end{array}$ & - & 0.863 & - & - \\
\hline $\begin{array}{l}\text { 3. Redefine the guiding policies and } \\
\text { decision-making practice (Q19) }\end{array}$ & - & 0.688 & - & - \\
\hline \multicolumn{5}{|l|}{ Innovation $(\alpha=0.799)$} \\
\hline 1. Innovation throughput mechanism (Q31) & - & - & 0.752 & - \\
\hline 2. Exploration of new digital business models (Q32) & - & - & 0.678 & - \\
\hline 3. Dedicated innovation function (Q33) & - & - & 0.635 & - \\
\hline 4. Transformational culture (Q9) & - & - & 0.627 & - \\
\hline \multicolumn{5}{|l|}{ Resource attainment $(\alpha=0.864)$} \\
\hline 1. Innovative financing models (Q35) & - & - & - & 0.783 \\
\hline 2. Creative partnership (Q36) & - & - & - & 0.747 \\
\hline 3. Procurement strategies (Q34) & - & - & - & 0.474 \\
\hline
\end{tabular}

Note: Extraction method: principal axis factoring; rotation method: varimax with Kaiser normalisation; rotation converged in seven iterations; coefficients less than 0.4 have been suppressed to allow for easy interpretation.

$M \& E$, monitoring and evaluation.

\section{Information technology and non-information technology leaders' perceptions}

As the EFA analysis revealed four underlying factors of ODT success, the hypotheses are proposed as follows:

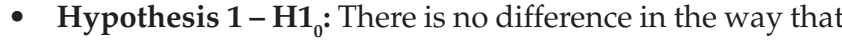
IT and non-IT leaders perceive customer centricity as an underlying success factor of ODT.

- Hypothesis $2-\mathrm{H}_{0}$ : There is no difference in the way that IT and non-IT leaders perceive governance as an underlying success factor of ODT.

- Hypothesis $3-\mathrm{H}_{0}$ : There is no difference in the way that IT and non-IT leaders perceive innovation as an underlying success factor of ODT. 
- Hypothesis 4- $\mathrm{H}_{0}$ : There is no difference in the way that IT and non-IT leaders perceive resource attainment as an underlying success factor of ODT.

The results of the Kruskal-Wallis $\mathrm{H}$ test $(p>0.05)$ showed that the median scores of the four factors were not statistically significantly different between IT leaders $(n=45)$ and non-IT leaders $(n=50)$. Therefore, the null hypothesis (H0) for each of the four factors, was retained, suggesting that there is no difference in the way that IT leaders and non-IT leaders perceive underlying success factors of ODT initiatives.

In addition, the median scores for all four factors were not statistically significantly different between IT leaders and non-IT leaders (customer centricity: $X^{2}(1)=0.406, p=0.521$; governance: $\mathrm{X}^{2}(1)=0.378, p=0.539$; innovation: $\mathrm{X}^{2}(1)=1.559$, $p=0.212$; resource attainment: $\left.X^{2}(1)=0.125, p=0.723\right)$. Therefore, the null hypothesis (H0) for all four factors was retained in support of the overall research hypothesis (Hypothesis 1). There is no difference in the way that IT managers and non-IT managers perceive customer centricity as the most important dimension for internal ODT. The hypothesis test summary with all $p$-values can be viewed in Table 6 .

\section{Discussion}

\section{Towards an organisational digital transformation assessment instrument}

According to Boström and Celik (2017), many assessment instruments in academic literature are developed without sufficient research and methodological rigour to robustly verify the validity and reliability of the instrument. In contrast, this research sought to empirically establish the reliability, face value validity, content validity, and convergent and divergent validity of underlying success factors for ODT initiatives previously suggested in the literature. By conducting statistical tests to determine the relationship among items (Creswell 2012), the validity based on internal structure was established. Principal axis factoring analysis confirmed the existence of four dimensions of underlying factors of a successful ODT initiative. These dimensions are (1) customer centricity, (2) governance, (3) innovation and (4) resource attainment. The findings are congruent with the arguments made by Kane et al. (2015) that the driver of ODT is strategy, not technology.

\section{Customer centricity}

Customer centricity is the proclivity of an organisation to focus on the interdisciplinary and organisational challenges associated with successfully designing and managing the customer experience (Lemon \& Verhoef 2016). Despite that, the relationship between ODT and user co-creations leading to process refinement have been discussed extensively (Berman 2012; Desmet et al. 2015; Sia, Soh \& Weill 2016; Wade 2015; Westerman et al. 2014) and a number of researchers have argued customer centricity to be an underlying success factor in ODT (Berman 2012; Desmet et al. 2015; Sebastian et al. 2017; Sia et al. 2016; Wade 2015; Westerman et al. 2014), the empirical studies on this topic remain scarce. Our findings suggest that this dimension includes the following factors: (1) a customer-centred approach in designing offerings (Q6); (2) mechanisms to keep abreast with changing customer needs (Q1); (3) process digitisation and re-engineering (Q14); (4) prioritisation of digital projects (Q15); and (5) experimentation with new technologies to meet customer needs (Q24).

The findings of this study revealed that the surveyed executives believe that organisations ought to adopt a usercentric approach when designing their offerings (Q6). Establishing effective mechanisms to keep abreast with changing customer needs is thus an imperative (Q1). However, revamping the digital capability alone will not lead to the desired impact unless the endeavour is complemented by refined processes (Kane et al. 2016). The participants further endorsed the importance of process reengineering (Q14) and prioritisation of digital projects (Q15). The survey also uncovered that the overall success of an ODT initiative can be affected by an organisation's ability to experiment with new technology to meet customers' needs (Q24). This finding concurs with research that finds that a firm's approach and capability to explore and exploit new digital technologies is an important success factor for ODT (Hess et al. 2016).

\section{Governance}

This dimension describes the guiding policies, decision structures, roles and responsibilities used to coordinate and steer the organisation's ODT initiatives (Westerman et al. 2012). In light of the wide-reaching repercussions of transforming the digital modus operandi and strategic intent

TABLE 6: SPSS output of the hypothesis test summary.

\begin{tabular}{|c|c|c|c|c|}
\hline Hypothesis number & Null hypothesis & Test & Significance & Decision \\
\hline H1 & $\begin{array}{l}\text { The distribution of the Factor } 1 \text { : Customer Centricity } \\
\text { REGR factor score is the same across categories of } \\
\text { respondent type ( } 1=\mathrm{IT} \text { and } 2=\text { non-IT). }\end{array}$ & Independent-samples Kruskal-Wallis test & 0.524 & Retain the null hypothesis. \\
\hline $\mathrm{H} 2$ & $\begin{array}{l}\text { The distribution of the Factor 2: Governance REGR } \\
\text { factor score is the same across categories of } \\
\text { respondent type }(1=\mathrm{IT} \text { and } 2=\text { non-IT). }\end{array}$ & Independent-samples Kruskal-Wallis test & 0.539 & Retain the null hypothesis. \\
\hline H3 & $\begin{array}{l}\text { The distribution of the Factor } 3 \text { : Innovation REGR } \\
\text { factor score is the same across categories of } \\
\text { respondent type ( } 1=\text { IT and } 2=\text { non-IT). }\end{array}$ & Independent-samples Kruskal-Wallis test & 0.212 & Retain the null hypothesis. \\
\hline H4 & $\begin{array}{l}\text { The distribution of the Factor } 4 \text { : Resource Attainment } \\
\text { REGR factor score is the same across categories of } \\
\text { respondent type }(1=\text { IT and } 2=\text { non-IT). }\end{array}$ & Independent-samples Kruskal-Wallis test & 0.723 & Retain the null hypothesis. \\
\hline
\end{tabular}

Note: Asymptotic significances are displayed. The significance level is 0.05 .

REGR, regression. 
of the organisation, effective governance has been deemed by some researchers as a critical lever for organisations to drive successful digital transformation (Boström \& Celik 2017; Westerman et al. 2012, 2014). This study found sufficient empirical evidence to support governance as a critical factor in driving the success of ODT. In particular, the findings suggest that leaders should ensure the following three factors are effectively addressed: (1) clearly defined monitoring and evaluation (M\&E) criteria and mechanisms (Q21); (2) security systems, standards and practices used to secure data (Q20); and (3) guiding policies and decision-making to steer the ODT initiatives (Q19).

Without defining these M\&E guidelines clearly and strategically, it will be difficult for leaders to keep abreast with the progress of the transformation process. It will also be harder for leaders to benchmark the progress against the business environment and competitors. Given that the business landscape today can change rapidly and disruptively, more scholarly attention should be placed on how leaders can ensure the M\&E proposed at the outset can remain robust and relevant throughout a transformation.

'Shadow IT' is a term often used to describe information technology systems and solutions built and used inside organisations without explicit organisational approval (Silic \& Back 2014). This poses severe threats of duplication of resources, wasted investment, inconsistency of business logics, security breaches and data loss or leaks. Failure to achieve effective governance can encourage different divisions within an organisation to develop their own workaround tactics, leading to the rise of shadow IT (Silic \& Back 2014).

\section{Innovation}

Innovation describes an organisation's ability to develop and implement new ideas (Svahn et al. 2017). With the rapid adoption of digitally enabled business models and smarter technology, consumers are increasingly favouring companies that provide innovative digital offerings (Sebastian et al. 2017; Wade 2015). This study validates innovation - both in the form of culture and practice - as an underlying success factor of ODT initiatives. Within the category of innovation, this study finds the following individual factors significant to successful ODT initiatives: (1) establishing an effective innovation throughput mechanism (Q31); (2) exploring new digital business models (Q32); (3) instituting a dedicated innovation function (Q33); and (4) cultivating a helpful transformational culture (Q9). These findings are in line with previous studies (Berman 2012; Oswald \& Kleinemeier 2017; Westerman et al. 2011), which assert that innovation, in both organisational practices and culture, affect the overall success of ODT.

In a recent study, Oswald and Kleinemeier (2017) linked innovation with ODT by developing a digital innovation and transformation framework. An organisation's capability to respond to new market opportunities in a timely fashion with innovative offerings is considered a critical advantage in today's business environment (Sebastian et al. 2017; Svahn et al. 2017). Our study concurred with these findings and suggested that organisations must have an effective mechanism to encourage innovation throughput (Q31) and to explore new digital business models (Q32). Considering that launching new innovative offerings and adopting new business models typically requires some level of intraorganisational collaboration and, at times, overhauling the traditional mode of operating, the importance of instituting a dedicated innovation function has been advocated (Hess et al. 2016). Our research concurred with this suggestion. In addition, the findings of our research also revealed the relevance of culture and further conformed with scholars who previously attributed the success of ODT initiatives in part to the innovative culture of the organisation (Boström \& Celik 2017; Desmet et al. 2015; Kane et al. 2015; Matt et al. 2015; Oswald \& Kleinemeier 2017; Sia et al. 2016; Singh \& Hess 2017; Wade 2015; Westerman et al. 2014).

\section{Resource attainment}

The final dimension of success factors identified by this research describes the organisation's ability to acquire resources in the form of funding, infrastructure, expertise and knowledge through partnership. Kane et al. (2016) find that $32 \%$ of digitally transformed companies establish effective external relationships or partnerships. We posit that these partnerships, both internal and external, enable the organisation to create viable funding models and financing mechanisms, aiding the ODT process. Considering that financial resources are crucial when organisations are pursuing ODT (Matt et al. 2015), especially in light of intense competition inside organisations for funding of other initiatives, organisations need to find creative funding mechanisms and partnership strategies to support their ODT initiatives (Hess et al. 2016; Westerman et al. 2014).

This study finds the following factors relevant to leaders as success factors of ODT: (1) innovative financing models and (2) creative partnerships with suppliers and procurement strategies. Even though collaboration effectiveness and agility in buyer-supplier relationships (Hesping \& Schiele 2015; Narayanan, Narasimhan \& Schoenherr 2015) as well as the procurement strategy selected (Ateş, Van Raaij \& Wynstra 2018) have been proposed as some of the key factors affecting an organisation's transformation performance, limited studies to date have been dedicated to how they affect the overall success of an ODT initiative.

\section{Statistically insignificant factors}

The study deliberately tested various technology-related factors, such as multichannel or omni-channel operations (Q13); platforms (Q26); integration of new systems with old IT legacy systems (Q22); and scaling of infrastructure on demand (Q23) for their relevance to the success of ODT. These factors were rejected by the survey participants. These findings are in accordance with the argument made by 
Kane et al. (2015) that the power of a digital transformation strategy lies in its scope and objectives rather than the technology. Even though scenario planning (Q2) and datadriven decision-making (Q3) were also excluded as factors, they may be better fitted with the overall strategy development process than with the ODT process.

Participant responses in this study refute the significance of aligning the strategies of different units (Q4) and embedding IT strategy in divisional strategies (Q5) as key underlying factors for successful ODT. Despite scholars having posited the importance of business-IT strategy alignment (Hess et al. 2016; Matt et al. 2015; Sia et al. 2016), whether various divisional strategies can achieve alignment should not greatly impact the outcome of an ODT initiative. In addition, it is the divisional strategies that shape the overall IT strategy. Organisational IT strategy should be aligned to the needs of the business divisions but not necessarily embedded in the divisional strategies.

Despite some evidence that 'senior leadership must really understand the power of digital technologies' for successful ODT (Kane et al. 2015), our research demonstrates that leaders' own technology awareness (Q7) is not a significant factor. This finding is not surprising, given that the leader's main responsibility is to set the strategic direction and that he or she can rely on technically competent staff to advise and drive the ODT process from that perspective. The potential reciprocity of digital capability and business strategy is an interesting topic for future study.

We further interpret the failure of silo prevention (Q12) and the coherency of organisational politics and the decentralisation of authority (Q8) showing up as significant factors of successful ODT as an indication that as long as leaders can set the direction firmly and hold people accountable, an ODT initiative does not need to address or control these factors intentionally.

Changing organisational structure (Q10) is another potential factor shown not to be statistically significant. Seeing that researchers have suggested that there are advantages and disadvantages to altering the existing corporate structure to increase the impact of ODT initiatives (Hess et al. 2016), the finding is not a surprising one. Several other change-related factors such as coordinating the portfolio of digital transformation initiatives (Q16), having a change campaign (Q17), establishing the engagement model with the rest of the organisation and external customers (Q27) and instituting urgency and efficiency through agile methodologies (Q18) were rejected as factors of a successful ODT. Further qualitative studies could be conducted to identify the most optimal change management mechanism to accompany ODT initiatives.

The involvement of external start-ups (Q25) may not always be necessary as some companies can rely on their internal resource and expertise to overcome ODT-related hurdles.
This research further suggests that to launch multilevel skills development (Q28), reshape employee key performance indicators (KPIs) (Q29) and implement rewards and recognition (Q30) may not be as critical as other factors identified. Scholars have suggested that outsourcing critical skills to increase organisational flexibility has become a common practice in recent years (Berman 2012). Our findings on the impact of KPIs, rewards and recognition towards ODT success contradict the recent suggestions made by Kontić and Vidicki (2018). However, Kontić and Vidicki did not empirically test these items despite the objective of their publication being to formulate a measurement tool for digital transformation. We therefore propose that further studies on these topics should be carried out.

\section{Conclusion}

In order to assist organisations to make effective investments in their pursuit of digital transformation, this article presented one of the few empirical studies on ODT. Postulates of key internal ODT factors of success from other studies have been theoretical in nature and lacked the necessary empirical evidence to reach conclusive inferences. This study identified underlying success factors of ODT initiatives suggested in extant literature. These were tested statistically, revealing four categories of significant factors. These are: (1) customer centricity, (2) governance, (3) innovation and (4) resource attainment. It was also shown through statistical analysis that IT and non-IT leaders do not substantially differ in their understanding of what these factors are.

Scholars and practitioners, possibly linking with other disciplines of management research (such as industrial sociology, digital road-mapping and agile methodology) can make use of this study to develop ODT assessment instruments, based on the underlying success factors identified in this article. As the factors of interest can be related to other constructs, future studies should also evaluate the nomological validity.

To succeed in digital transformation, big enterprises must continually keep abreast with changing customer needs and be highly disciplined in adopting user-centred approaches when designing their offerings. It is therefore imperative for leaders to create the audacious vision, strategy, process, divisions and culture that can encourage their employees to innovate and experiment with new technologies and business models. As no two organisations experience the same challenges, the M\&E criteria and mechanisms, as well as the guiding policies and decision structures to steer the ODT initiatives, must be thoroughly deliberated and contextualised. Taking such concerted efforts prior to embarking on the ODT journey will permit employees to prioritise the digital projects, create multilevel partnerships and explore innovative financing models and procurement strategies that can best address the unique challenges of the organisation. While ODT brings forth unmatched opportunities for growth and value creation, there will 
always be risks involved. Therefore, leaders must also purposefully derive the security systems, standards and practices to prevent and mitigate risks associated with refining the processes and revamping the infrastructure.

McGrath et al. (2016) posit that leaders must establish a clear way forward in three areas: the 'why', 'what' and 'how' of the digital strategy. Answers to these questions will have far-reaching implications for management and their organisations. Implications for management relate to some of the critical questions that managers need to ask and answer when pursuing ODT. The findings of this research will be helpful to leaders by prompting strategic questions such as: What constitutes effective ODT governance? What value will an ODT initiative bring to customers? How will the organisation fund an ODT initiative? With whom should an organisation partner or collaborate with, and how should this be done, to achieve effective ODT?

\section{Limitation and suggestions for future research}

Pohlmann (2004) suggests that factor structures are more stable when they are founded on large samples. The small sample size $(n=95)$ was the main limitation of this research; however, the PAF method was chosen specifically for its ability to recover weak factors when EFA is conducted with small sample sizes (De Winter \& Dodou 2012). It is important to note that even with large sample sizes, EFA is considered to be an error-prone procedure (Costello \& Osborne 2005). This research makes an inductive inference about the important determinants of the ODT and the field will benefit from future research to test the objectivity of this research. Confirmatory factor analysis can be used to confirm or reject the factor structure postulated in this research (Hurley et al. 1997), and future research can be conducted to unpack each construct identified in this research. Primarily, this study ought to serve as a foundation for later researchers for the establishment of an ODT assessment instrument, thus building on the critical success factors identified in this study.

\section{Acknowledgements}

This research stems from N.M.'s MBA research. The manuscript and the supplementary document submitted are the intellectual property of the co-authors.

\section{Competing interests}

The authors declare that they have no financial or personal relationship(s) that may have inappropriately influenced them in writing this article.

\section{Authors' contribution}

This research stems from N.M.'s MBA research, conducted under the supervision of J.C. P.A. made a significant, expert contribution.

\section{References}

Abolhassan, F., 2017, The drivers of digital transformation, Springer International Publishing, Cham.

Ateş, M.A., Van Raaij, E.M. \& Wynstra, F., 2018, 'The impact of purchasing strategystructure (mis) fit on purchasing cost and innovation performance', Journal of Purchasing and Supply Management 24(1), 68-82.

Barrett, P.T. \& Kline, P., 1981, 'Observation to variable ratio in factor analysis', Personality Study \& Group Behaviour 1(1), 23-33.

Benson, J. \& Clark, F., 1982, 'A guide for instrument development and validation', American Journal of Occupational Therapy 36, 789-800. https://doi.org/10.5014/ ajot.36.12.789

Berman, S.J., 2012, 'Digital transformation: Opportunities to create new business models', Strategic Leadership 40, 16-24. https://doi.org/10.1108/ 10878571211209314

Bharadwaj, A., El Sawy, O.A., Pavlou, P.A. \& Venkatraman, N., 2013, 'Digital business strategy: Toward a next generation of insight', MIS Quarterly, 37(2), 471-482.

Boström, E., \& Celik, O.C., 2017, 'Towards a maturity model for digital strategizing: A qualitative study of how an organization can analyze and assess their digital business strategy', Dissertation, Dept. of Informatics Umeå University.

Costello, A.B. \& Osborne, J.W., 2005, 'Best practices in exploratory factor analysis: Four recommendations for getting the most from your analysis', Practical assessment, research \& evaluation 10(7), 1-9.

Creswell, J.W., 2012, Educational research, 4th edn., Pearson, Cambridge.

De Winter J.C.F., Dodou, D. \& Wieringa, P.A., 2009, 'Exploratory factor analysis with small sample sizes', Multivariate Behavioural Research 44, 147-181. https://doi. org $/ 10.1080 / 00273170902794206$

De Winter, J.C. \& Dodou, D., 2012, 'Factor recovery by principal axis factoring and maximum likelihood factor analysis as a function of factor pattern and sample size', Journal of Applied Statistics 39(4), 695-710.

Desmet, D., Duncan, E., Scanlan, J. \& Singer, M., 2015, 'Six building blocks for creating a high-performing digital enterprise', McKinsey Digital 1-8.

Fabrigar, L.R., MacCallum, R.C., Wegener, D.T. \& Strahan, E.J., 1999, 'Evaluating the use of exploratory factor analysis in psychological research', Psychological Methods 4 272-299. https://doi.org/10.1037/1082-989X.4.3.272

Fitzgerald, M., Kruschwitz, N., Bonnet, D. \& Welch, M., 2013, 'Embracing digital technology: A new strategic imperative', MIT Sloan Management Review 55(2), $1-12$.

Gerth, A.B. \& Peppard, J., 2016, 'The dynamics of $\mathrm{ClO}$ derailment: How ClOs come undone and how to avoid it', Business Horizon 59, 61-70. https://doi. org/10.1016/j.bushor.2015.09.001

Hesping, F. \& Schiele, H., 2015, 'Purchasing strategy development: A multi-level review', Journal of Purchasing and Supply Management 21(2), 138-150.

Hess, T., Benlian, A., Matt, C. \& Wiesböck, F., 2016, 'Options for formulating a digital transformation strategy', MIS Quarterly Executive 15, 123-139.

Hurley, A.E., Scandura, T.A., Schriesheim, C.A., Brannick, M.T., Seers, A., Vandenberg, R.J. et al., 1997, Exploratory and confirmatory factor analysis: Guidelines, issues, and alternatives', Journal of Organizational Behavior 18(6), 667-683.

Kane, G.C., Palmer, D., Philips, A.N., Kiron, D., Buckley, N., Phillips, A.N. et al., 2015, 'Strategy, not technology, drives digital transformation', MIT Sloan Management Review, 14 July, 2015, pp. 1-25, viewed from http://sloanreview.mit.edu/projects/ strategy-drives-digital-transformation/

Kane, G.C., Palmer, D., Phillips, A.N., Kiron, D. \& Buckley, N., 2016, 'Aligning the organization for its digital future', MIT Sloan Management Review, 26 July, 2016,
pp. 1-29, viewed from https://sloanreview.mit.edu/projects/aligning-for-digitalpp. $1-29$,
future/

Kontić, L. \& Vidicki, Đ., 2018, 'Strategy for digital organization: Testing a measurement tool for digital transformation', Strategic Management 23(1), 29-35. https://doi. org/10.5937/StraMan1801029K

Lemon, K.N. \& Verhoef, P.C., 2016, 'Understanding customer experience throughout the customer journey', Journal of Marketing 80(6), 69-96. https://doi. org/10.1509/jm.15.0420

Matt, C., Hess, T. \& Benlian, A., 2015, 'Digital transformation strategies', Business \& Information Systems Engineering 57, 339-343. https://doi.org/10.1007/s12599015-0401-5

McGrath, K., 2016, 'Identity verification and societal challenges: Explaining the gap between service provision and development outcomes,' MIS Quarterly 40(2), 485-500.

Narayanan, S., Narasimhan, R. \& Schoenherr, T., 2015, 'Assessing the contingent effects of collaboration on agility performance in buyer-supplier relationships', Journal of Operations Management 33, 140-154.

Norman, G., 2010, 'Likert scales, levels of measurement and the "laws" of statistics', 15(5), 625-632. https://doi.org/10.1007/s10459-010-9222-y

Oswald, G. \& Kleinemeier, M. (eds.), 2017, 'Shaping the digital enterprise', Springer International Publishing, Berlin.

Pohlmann, J.T., 2004, 'Use and interpretation of factor analysis in the journal of educational research: 1992-2002', Journal of Educational Research 98, 14. https:// doi.org/10.3200/JOER.98.1.14-23

Saunders, M.N.K., Thornhill, A. \& Lewis, P., 2015, Research methods for business students, Pearson, London. 
Sebastian, I.M., Ross, J.W., Beath, C., Mocker, M., Moloney, K. G., \& Fonstad, N.O., 2017, 'How big old companies navigate digital transformation', MIS Quarterly Executive 16(3), 197-213.

Sia, K.S., Soh, C. \& Weill, P., 2016, 'How DBS bank pursued a digital business strategy', MIS Quarterly Executive 15, 105-121.

Silic, M., \& Back, A., 2014, 'Shadow IT-A view from behind the curtain', Computers \& Security $45,274-283$.

Singh, A. \& Hess, T., 2017, 'How chief digital officers promote the digital transformation of their companies', MIS Quarterly Executive 16, 1-17.

Soule, D., Puram, A., Westerman, G., \& Bonnet, D., 2015, Becoming a digita organization: The journey to digital dexterity, viewed n.d., from https://ssrn.com/ abstract $=2697688$

Stief, S.E., Eidhoff, A.T. \& Voeth, M., 2016, 'Transform to succeed: An empirical analysis of digital transformation in firms', World Academy of Science, Engineering and of digital transformation in firms', World Academy of Science, Engineering and Business and Industrial Engineering 10(6), 1833-1842.

Svahn, F., Mathiassen, L., \& Lindgren, R., 2017, 'Embracing digital innovation in incumbent firms: how Volvo cars managed competing concerns', MIS Quarterly 41(1), 239-253

The Economist Intelligence Unit, 2016, Digitising IT: Leadership for the next phase of digital transformation: A report by The Economist Intelligence Unit, viewed n.d. from https://h22168.www2.hpe.com/docs/sap/accelerate/DigitisingITwebFinal.pdf
Wade, M., 2015, Digital business transformation - A conceptual framework, 1st edn., Global Center for Digital Business Transformation: IMD and Cisco Initiative, Switzerland.

Wang, F.K. \& Du, T.C.T., 2000, 'Using principal component analysis in process performance for multivariate data', Omega 28, 185-194. https://doi.org/10.1016/ S0305-0483(99)00036-5

Westerman, G., Bonnet, D., Mc \& Mcaffee, A., 2014, Leading digital: Turning technology into business transformation, 1st edn., Harvard Business Review, Boston, MA.

Westerman, G., Calméjane, C., Bonnet, D., Ferraris, P. \& McAfee, A., 2011, Digital transformation: A roadmap for billion-dollar organizations, MIT Center for Digital Business Capgemini Consult viewed nd from https://www capgemini.com/wpBusins/uploads/2017/07/Digital_Transformatios:_w_ Map for BillionDollar_Organizations.pdf

Westerman, G., Tannou, M., Bonnet, D., Ferraris, P. \& McAfee, A., 2012, 'The digital advantage: How digital leaders outperform their peers in every industry', MIT Sloan Management and Capgemini Consult, MA 2, 2-23.

Yong, A.G. \& Pearce, S., 2013, 'A beginner's guide to factor analysis: Focusing on exploratory factor analysis', Tutorials in Quantitative Methods for Psychology 9 , 79-94. https://doi.org/10.20982/tqmp.09.2.p079

Zikmund, W.G., Babin, B.J., Carr, J.C. \& Griffin, M., 2010, Business research methods, 8th edn., South-Western Cenage Learning, Boston. 